\title{
Haemodynamic effects of short term intravenous amiodarone for hypertrophic cardiomyopathy
}

\author{
ANGELO BRANZI, CLAUDIO RAPEZZI, PLACIDO M BENENATI, \\ GIORGIO BINETTI, GIANCARLO PIOVACCARI, MIRKA BACCHI, \\ RENZO RONCUZZI, ROMANO ZANNOLI, BRUNO MAGNANI
}

From the Istituto di Malattie dell' Apparato Cardiovascolare, Università degli Studi di Bologna, Bologna, Italy

SUMMARY The haemodynamic effects of an intravenous amiodarone infusion $(5 \mathrm{mg} / \mathrm{kg}$ for 10 minutes) were measured in ten patients with hypertrophic cardiomyopathy (two with a left ventricular outflow gradient at rest) five, 15, and 30 minutes after drug administration. Mean (SD) pulmonary capillary wedge pressure rose significantly at five and 15 minutes (from $12 \cdot 3(6 \cdot 2) \mathrm{mm}$ $\mathrm{Hg}$ to $17 \cdot 6(9 \cdot 2)$ and to $16 \cdot 2(8 \cdot 6)$ ) with a subsequent tendency to fall to control values at 30 minutes. Mean right atrial and right ventricular end diastolic pressures increased from $3.6(1.8) \mathrm{mm} \mathrm{Hg}$ to $7 \cdot 3(3 \cdot 1)$ and from $6 \cdot 3(2 \cdot 4)$ to $9 \cdot 8(3 \cdot 2) \mathrm{mm} \mathrm{Hg}$ respectively at 30 minutes. The increase in filling pressures was paralleled by a decrease of left ventricular max $\mathrm{dP} / \mathrm{dt}$ from 1522 (414) to 1372 (327) to 1316 (338) and to 1326 (379) five, 15, and 30 minutes after infusion. Despite this slight negative inotropic effect, cardiac index and stroke volume index were unchanged or slightly increased, possibly because of the decrease in systemic vascular resistance (from $1326(330)$ dyn s cm $\mathrm{cm}^{-5} / \mathrm{m}^{2}$ to 1152 (285)). In both patients with outflow gradient the pressure gradient at rest decreased (from 110 to 65 and from 85 to $65 \mathrm{~mm} \mathrm{Hg}$ ) through a reduction of left ventricular systolic pressure.

Thus short term intravenous infusion of amiodarone is safe in patients with hypertrophic cardiomyopathy. The main changes were a mild depression of ventricular contractility, which was well tolerated and adequately compensated for by a decrease in afterload.

Over the past few years amiodarone has become widely accepted as a first line management of arrhythmias in patients with hypertrophic cardiomyopathy. ${ }^{1-3}$ Its haemodynamic action after intravenous administration has been extensively studied in patients with coronary artery disease $\mathrm{e}^{4-6}$ but no data are available on the short term effects in hypertrophic cardiomyopathy. Because the pathophysiology of hypertrophic cardiomyopathy is unique, the haemodynamic effects seen in other cardiac diseases may not necessarily be found in this disorder. For this reason we studied the haemodynamic effects of intravenous amiodarone in 10 patients with hypertrophic cardiomyopathy.

\section{Patients and methods}

\section{PATIENTS}

Ten patients (eight men and two women, aged 36 (13)

Requests for reprints to Professor Angelo Branzi, Istituto di Malattie dell'Apparato Cardiovascolare, Via Massarenti no 9, 40138 Bologna, Italy.

Accepted for publication 3 August 1987 years (mean (SD)) (range 19 to 55 years)) were studied after giving their informed consent. They were the first ten patients referred to this hospital who were not already taking oral amiodarone when the study was planned. Only two patients had a left ventricular outflow gradient $(110$ and $85 \mathrm{~mm} \mathrm{Hg}$ ). Initial evaluation included 48 hours electrocardiographic recording (Holter), which showed paroxysmal atrial fibrillation or supraventricular tachycardia or both in six patients and runs of ventricular tachycardia in four.

Table 1 summarises patient characteristics, predominant symptoms, New York Heart Association functional class, distribution and extent of left ventricular hypertrophy, and 48 hour Holter data. The distribution of left ventricular hypertrophy was classified according to Maron et $\mathrm{al}^{7}$ based on cross sectional echocardiographic findings. The presence or absence of systolic anterior movement of the mitral valve on the echocardiogram was noted.

CATHETERISATION PROCEDURES

All patients had standard right and left sided cardiac 
Table 1 Patients' characteristics

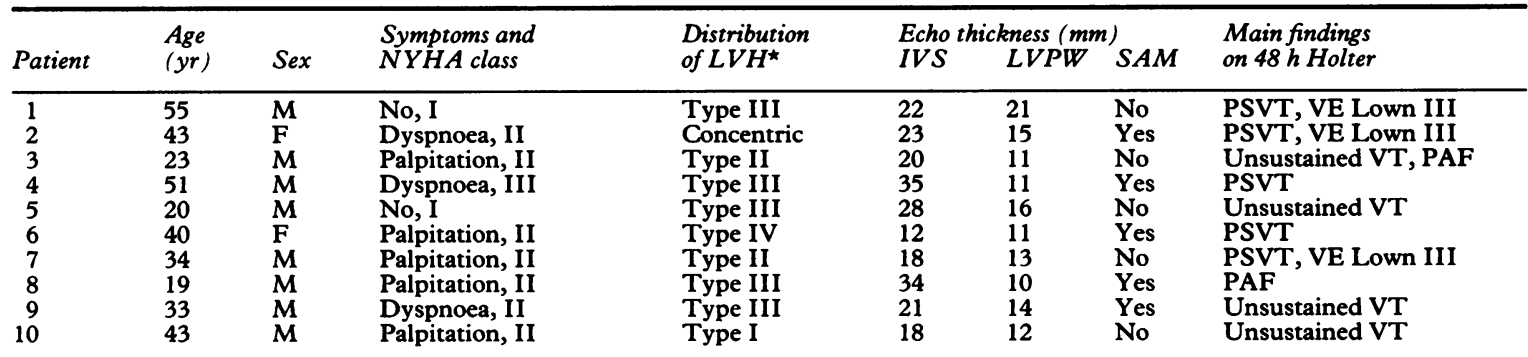

LVH, left ventricular hypertrophy; IVS, interventricular septum; LVPW, left ventricular posterior wall; SAM, systolic anterior movement; PSVT, paroxysmal supraventricular tachycardia; VE, ventricular extrasystoles; VT, ventricular tachycardia; PAF, paroxysmal atrial fibrillation.

^According to Maron et al. ${ }^{7}$

catheterisation without premedication after an overnight fast. A 7F Swan-Ganz thermodilution catheter was inserted percutaneously from the right femoral vein with its tip in a pulmonary artery and the proximal lumen in the right atrium. A $8 \mathrm{~F}$ double lumen micromanometer tip Millar catheter was advanced from the right femoral artery in an arterial sheath to the body of the left ventricle. We ensured that entrapment, spurious gradient, or arrhythmias would not occur. Systemic arterial pressure was monitored from the side arm of the arterial sheath $(8 \mathrm{~F})$ or from a second arterial line if the quality of the pressure wave from the sheath was unsatisfactory.

Cardiac output was measured in triplicate by the thermodilution technique; heart rate (mean of six beats) and rhythm were recorded by the electrocardiogram.

\section{MEASUREMENTS}

Reference 0 for pressure measurements was set at mid-chest level. The micromanometer was calibrated with the fluid filled system of the lumen of the Millar catheter itself. All pressure measurements were the mean of 5-10 consecutive beats. When we recorded pressure-derived contractility and relaxation indexes, the patients were asked to hold their breath at mid-inspiration. We calculated the following variables from pressure and flow measurements: systemic vascular resistance (mean blood pressure/ cardiac output); pulmonary vascular resistance (mean pulmonary artery - pulmonary capillary wedge pressure/cardiac output); cardiac index (cardiac output/body surface area); stroke volume (cardiac output/heart rate); peak positive left ventricular pressure first time derivative $(\max \mathrm{dP} / \mathrm{dt})$; peak negative $\mathrm{dP} / \mathrm{dt}$; and time constant of left ventricular pressure fall after the peak negative $\mathrm{dP} / \mathrm{dt}(\mathrm{T})$. Left ventricular and pulmonary capillary wedge pressures were recorded at a paper speed of $200 \mathrm{~mm} / \mathrm{s}$ and the left ventricular pressure values taken at $10 \mathrm{~ms}$ intervals from the peak negative $\mathrm{dP} / \mathrm{dt}$ to the end of isovolumetric diastole determined by the point at which left ventricular pressure crosses the wedge pressure tracing and these data were fitted by the method of least squares to the function $P=e^{A t+B}$. The time constant $T$ equals $1 /-A$, where $A$ is the slope of $\ln \mathrm{P}$ plotted against time and expressed as $^{-1}$. $^{8}$

\section{Study protocol}

Twenty minutes were allowed for stabilisation before we took a complete set of baseline measurements. Then amiodarone $(5 \mathrm{mg} / \mathrm{kg}$ body weight $)$ was infused over ten minutes. We used the commercially available preparation (Cordarone) containing the diluent Tween 80. Haemodynamic measurements were repeated five, 15, and 30 minutes after the end of the injection. Cardiac output and the derived variables were only measured at 30 minutes.

\section{Statistical evaluation}

Statistical analysis was performed by Student's $t$ test for paired data. A p value $<\mathbf{0 . 0 5}$ was considered to be significant. Values are expressed as mean (1 SD).

\section{Results}

Table 2 shows individual and mean haemodynamic data. Figures 1, 2, and 3 show the individual changes in pulmonary capillary wedge pressure, left ventricular end diastolic pressure, $\max \mathrm{dP} / \mathrm{dt}$, peak negative $\mathrm{dP} / \mathrm{dt}$, time constant $\mathrm{T}$, cardiac index, stroke volume, and systemic vascular resistance. Five and 15 minutes after amiodarone pulmonary wedge pressure rose significantly whereas at 30 minutes there was tendency to return to control values (fig 1). In one of the two patients (fig 1 ) with a left ventricular outflow gradient, pulmonary capillary wedge pressure rose to $30 \mathrm{~mm} \mathrm{Hg}$ at five and 15 minutes and returned to baseline value at 30 minutes in the absence of symptoms and clinical problems. 
Table 2 Mean haemodynamic data obtained at baseline and after amiodarone infusion

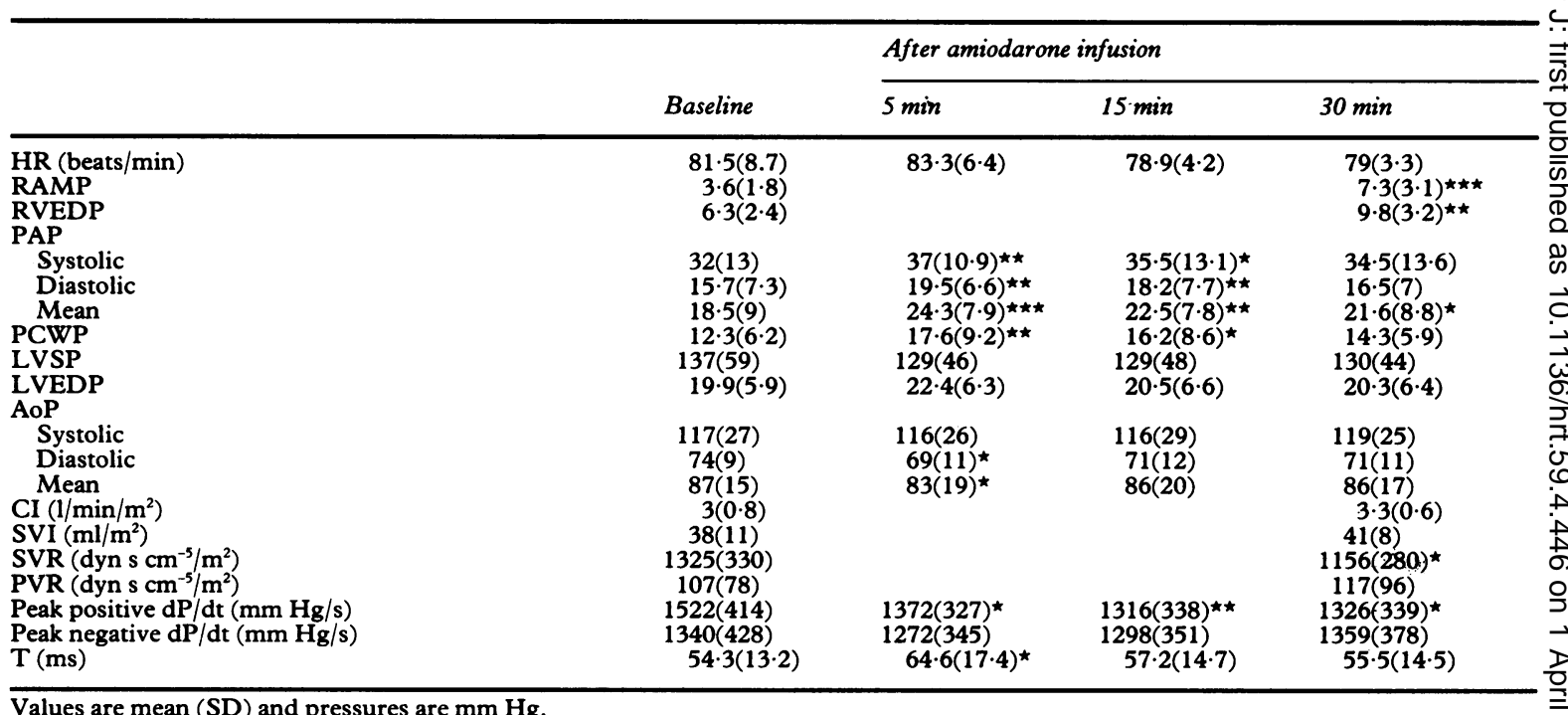

Values are mean (SD) and pressures are $\mathrm{mm} \mathrm{Hg}$.

HR, heart rate; RAMP, right atrial mean pressure; RVEDP, right ventricular end diastolic pressure; PAP, pulmonary arterial pressure; $\vec{\theta}$ PCWP, pulmonary capillary wedge pressure (mean); LVSP, left ventricular systolic pressure; LVEDP, left ventricular end diastolic $\infty$ pressure; AoP, aortic pressure; CI, cardiac index; SVI, stroke volume index; SVR, systemic vascular resistance; PVR, pulmonary vascular $\infty$ resistance.

$\mathrm{T}$ is the time constant of the fall in left ventricular pressure.

$\star p<0.05, \star \star 0.01, \star \star \star 0.001$ (versus baseline).

A table of results for individual patients is available from the authors.
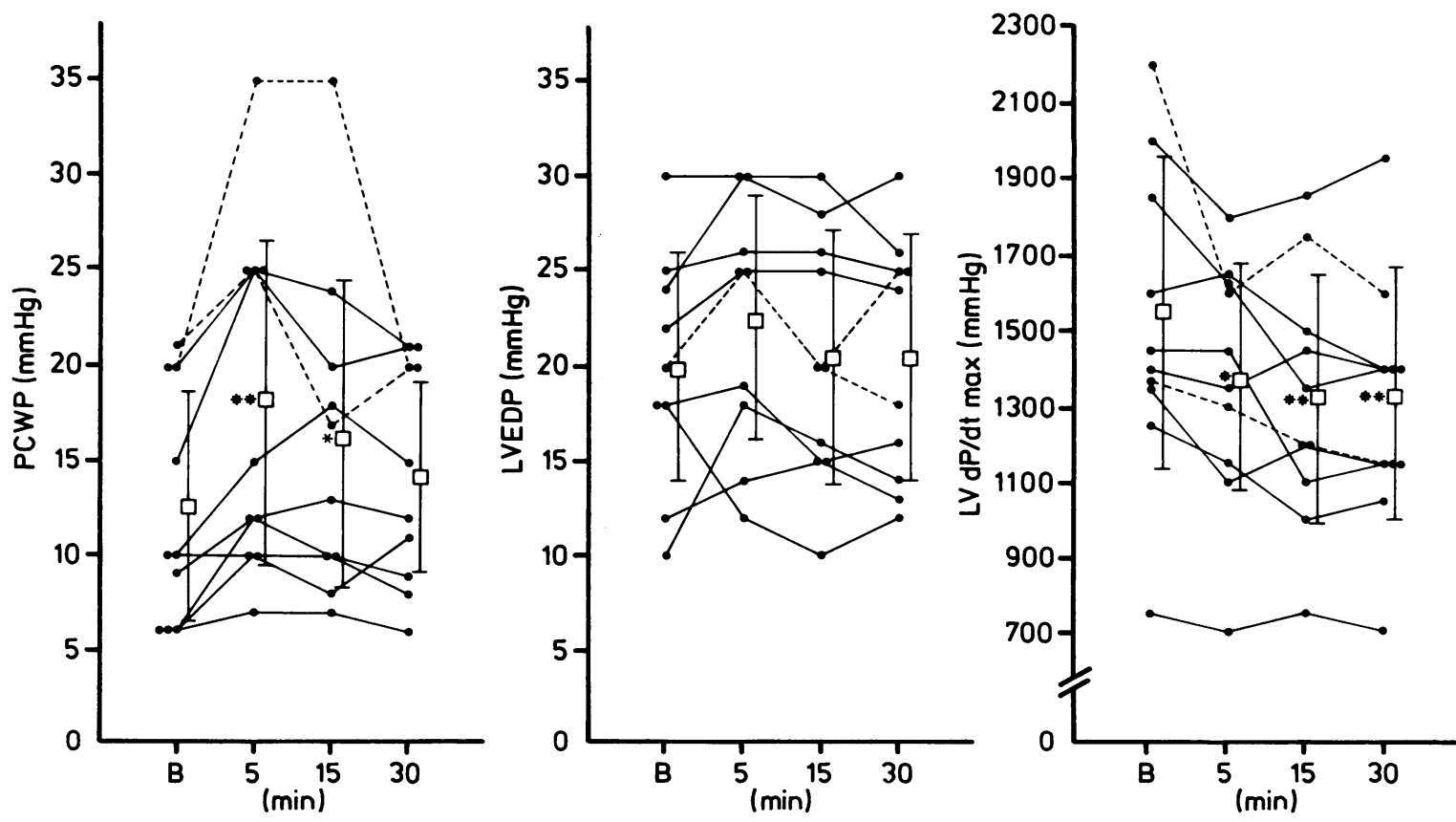

Fig 1 Effects of amiodarone infusion on mean pulmonary capillary wedge pressure (PCWP), left ventricular end diastolic pressure ( $L V E D P)$, and left ventricular $(L V)$ max $d P / d t$. Individual and mean $(S D)$ values are shown at baseline (B) and five, 15, and 30 minutes after amiodarone infusion. The dotted lines identify the two patients with left ventricular outflow gradient at rest. ${ }^{\star} p<0.05$ vs baseline value; ${ }^{\star} p<0.01$ vs baseline value. 

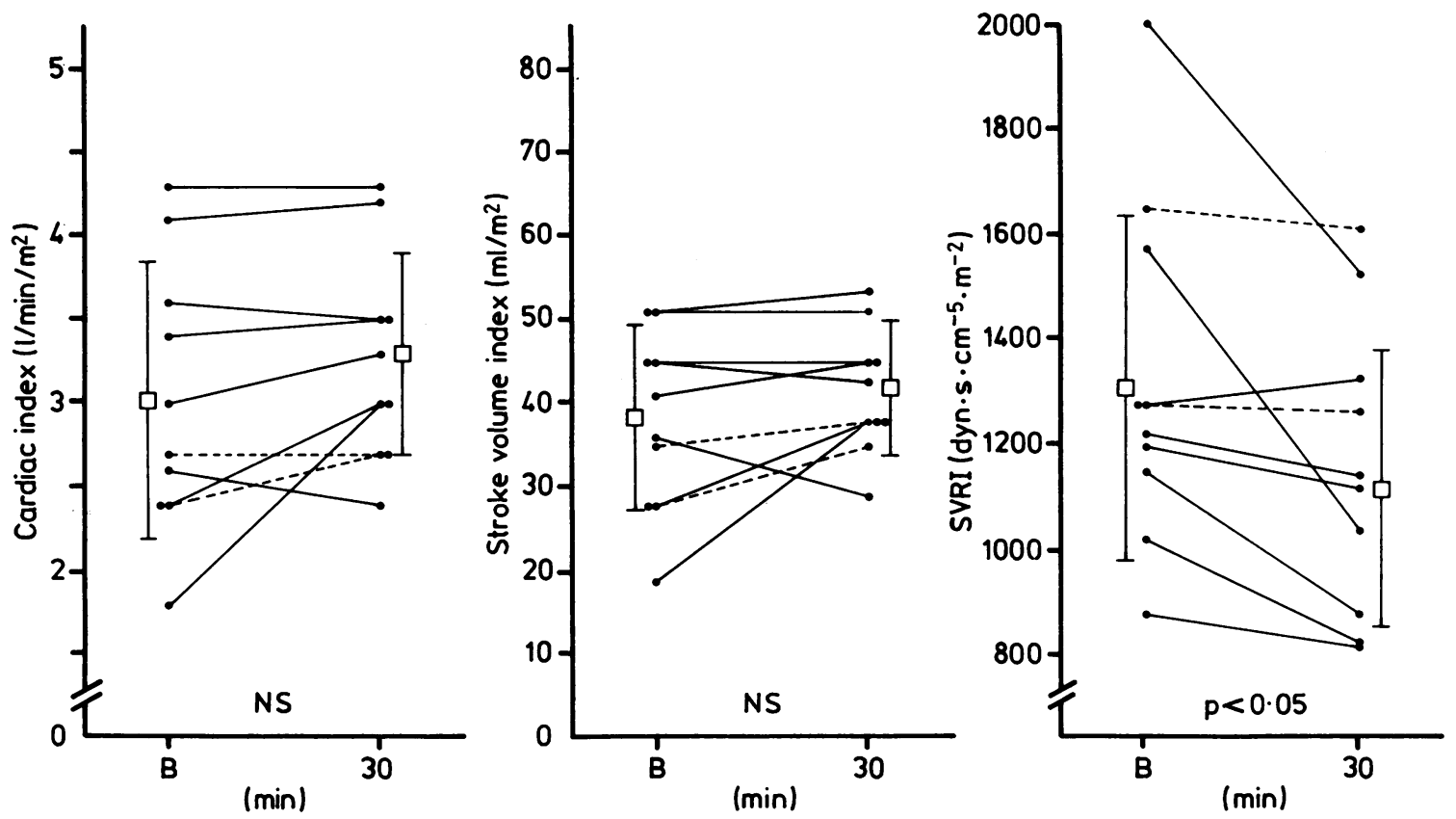

Fig 2 Effects of amiodarone infusion on cardiac index, stroke volume index, and systemic vascular resistance index (SVRI). Individual and mean (SD) values are shown at baseline $(B)$ and 30 minutes after amiodarone infusion. The dotted lines identify the two patients with left ventricular outflow gradient at rest.
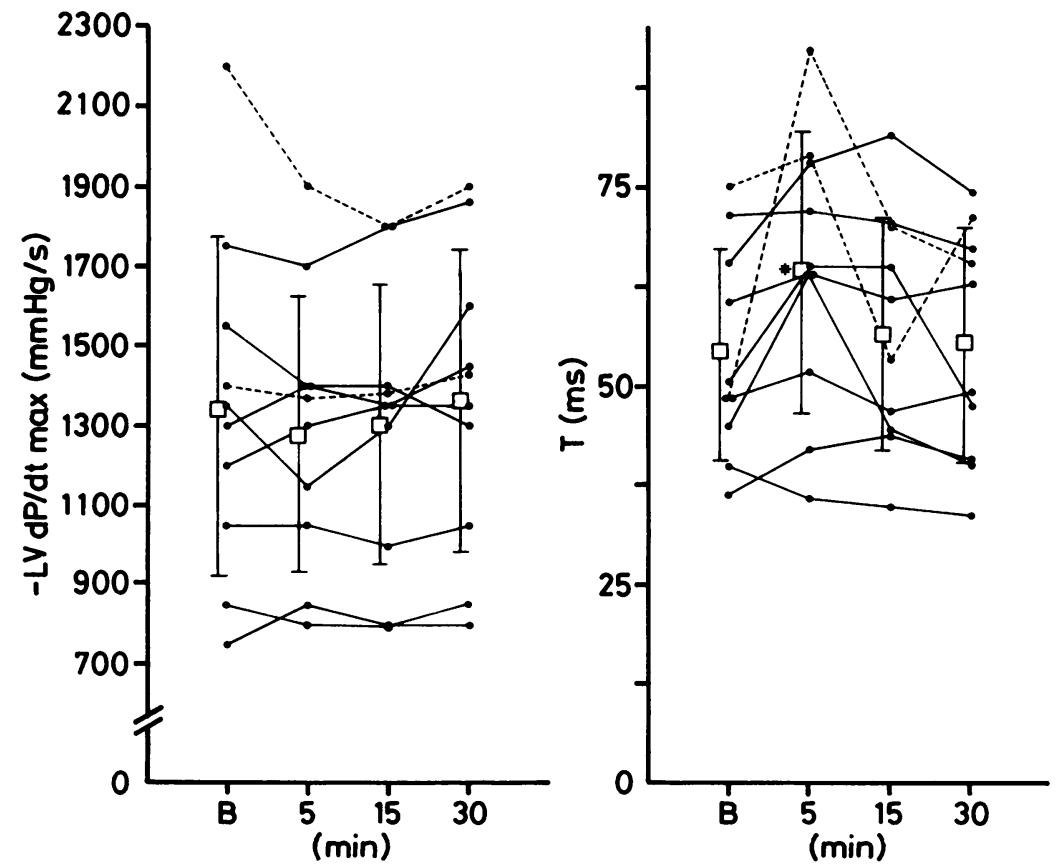

Fig 3 Effects of amiodarone infusion on left ventricular peak negative dP/dt ( $-L V d P / d t$ max) and time constant (T) of the fall in left ventricular pressure. Individual and mean ( $S D)$ values are shown at baseline $(B)$ and five, 15, and 30 minutes after amiodarone infusion. The dotted lines identify the two patients with left ventricular outflow gradient at rest. ${ }^{\star} p<0 \cdot 05$ vs baseline. 
There was a smaller and not statistically significant increase in left ventricular end diastolic pressure. The increase in pulmonary wedge pressure was paralleled by a decrease in $\max \mathrm{dP} / \mathrm{dt}$ that remained statistically significant at 30 minutes. These results are consistent with a slight negative inotropic action of amiodarone. The finding that cardiac index and stroke volume were unchanged or increased slightly at 30 minutes, however, may be the result of the decrease in peripheral resistance (fig 2). In fact mean systemic vascular resistance was significantly reduced at $\mathbf{3 0}$ minutes. In five patients there was a decrease while in the other five there was no change or a minimal reduction (fig 2 ). Heart rate did not change significantly at any time. Mean right atrial pressure and the right ventricular end diastolic pressure were also increased. The time constant $T$ rose significantly at five minutes, indicating a transient reduction in relaxation.

\section{Discussion}

The management of cardiac arrhythmias is a major task in patients with hypertrophic cardiomyopathy. Oral treatment is the usual treatment but often intravenous administration may be required, for example in patients who are haemodynamically unstable during the arrhythmic phases or in between them, and in whom immediate interruption of the arrhythmia or its prevention is important.

Although amiodarone is an effective antiarrhythmic drug for patients with hypertrophic cardiomyopathy, ${ }^{1-3}$ it may take several days to reach therapeutic concentrations in the blood and suppression of arrhythmia, ${ }^{9-11}$ even with a large oral loading dose. Intravenous bolus injection of amiodarone has been demonstrated to be effective in controlling various supraventricular and ventricular arrhythmias. ${ }^{12-14}$ Intravenous administration is usually followed by continuous infusion as a long term oral regimen is started. This approach shortens the loading period.

The effect of long term oral amiodarone on left ventricular function in hypertrophic cardiomyopathy has been reported recently. ${ }^{15}{ }^{16}$ Sugrue et al studied systolic and diastolic left ventricular function at rest with serial radionuclide angiograms and found that ejection fraction and left ventricular filling indices were not altered.$^{15}$ Paulus et al reported a negative effect on rest and exercise haemodynamic function with no effect on echocardiographic relaxation indices. ${ }^{16}$ In that study the significant increase in left ventricular filling pressures at rest and the higher pulmonary capillary wedge pressures during exercise at identical workloads are consistent with a negative inotropic action of amiodarone.
Information on the haemodynamic effects of intravenous amiodarone has been obtained from studies on normal volunteers ${ }^{17}{ }^{18}$ or patients with ischaemic heart disease ${ }^{419}$ or depressed left ventricular function of different causes. ${ }^{52}$ In these conditions intravenous amiodarone had both negative inotropic and peripheral vasodilatory effects. The consensus is, however, that the haemodynamic changes are a consequence of the combined effects of the drug and its diluent Tween 80. Sicart et al compared the effects of amiodarone with solvent and pure Tween $80 .{ }^{17}$ They concluded that the early vasodilatation was primarily but not exclusively caused by Tween 80 , while the later reduction in contractility was caused by amiodarone itself. The effects induced by the diluent lasted only up to four minutes. Bellotti et al infused amiodarone not dissolved in Tween 80 into patients with congestive heart failure caused by chronic Chagas's disease and found both a negative inotropic effect and a peripheral vasodilatation. ${ }^{20}$

In the previously reported studies amiodarone was injected at doses of $5-10 \mathrm{mg} / \mathrm{kg}$ over periods of $1-5$ minutes. A more gradual intravenous administration of the drug has been advised to avoid the possible acute hypotension. ${ }^{21}$ In the present study we increased the time of infusion to 10 minutes and started to measure the haemodynamic effect five minutes after the end of the infusion. The haemodynamic changes that we measured are therefore more likely to reflect the action of the drug alone.

In the present study the main effect of short term intravenous amiodarone was a mild depression of myocardial function. This was shown by an increase in right and left filling pressures and by a decrease in left ventricular $\max \mathrm{dP} / \mathrm{dt}$. Simultaneous systemic vasodilatation, however, compensated for the effect on contractility and cardiac output was maintained. Despite the decrease in systemic vascular resistance, there was no reflex increase in heart rate. This finding can be explained by the drug's properties of noncompetitive blockade of both $\alpha$ and $\beta$ receptors. ${ }^{22-24}$ Left ventricular $\mathrm{dP} / \mathrm{dt}$ is load dependent, so the of observed reduction in this variable could have been $N$ caused by a reduction in systemic vascular resistance $N_{\omega}$ itself, unassociated with any reflex adrenergic response. A true decrease in contractility is, however, a 0 more likely explanation because max $\mathrm{dP} / \mathrm{dt}$ also fell in those patients who did not show any reduction of systemic vascular resistance.

The two patients with left ventricular outflow gradient showed the same haemodynamic changes that were seen in the others: in both cases the gradient decreased because there was a moderate reduction of left ventricular systolic pressure. 
The ability of amiodarone to reduce the afterload seemed to be most relevant in determining the behaviour of the stroke volume. When the patients who showed a decrease in afterload (as reflected by systemic resistance or by the left ventricular outflow gradient) are considered separately from those in whom the afterload did not change, it can be seen that $\max \mathrm{dP} / \mathrm{dt}$, pulmonary capillary wedge pressure, and left ventricular end diastolic pressure changed in the same direction or did not differ significantly in the two subgroups, while stroke volume increased only in those patients who showed a decrease in afterload (fig 4). Since filling pressures also rose in these patients we believe that the reduction in afterload overcompensated for the reduction in contractility. This would imply an increase in left ventricular volumes.

We interpreted the increase in filling pressures as a negative inotropic effect of amiodarone. This finding could also be explained by a reduction in ventricular compliance. Amiodarone did not modify the peak negative $\mathrm{dP} / \mathrm{dt}$ but it did significantly increase the time constant of left ventricular pressure fall $(T)$ at five minutes, which indicates a reduction in relaxation (fig 3). This effect was transient and did not persist at 30 minutes when the simultaneous changes in stroke volume, systemic vascular resistance, contractility, and filling pressure were considered.

The results of the present study indicate that short term intravenous amiodarone may be given safely to

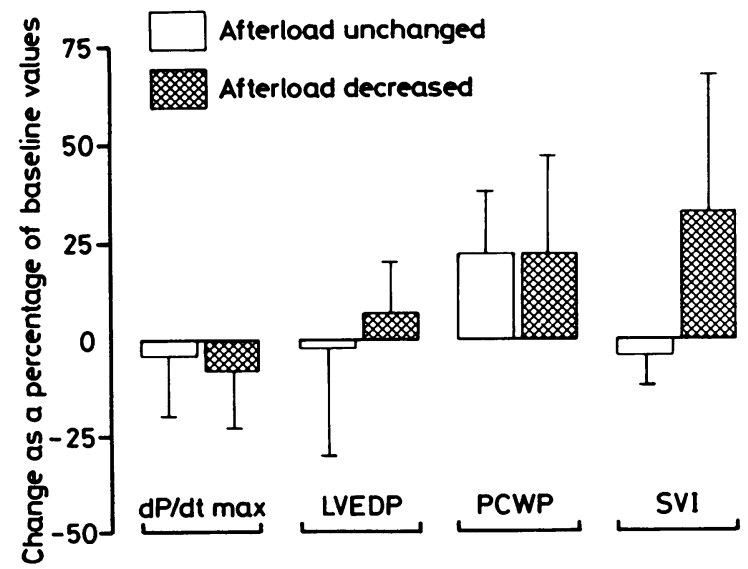

Fig 4 Change (mean ( $S D$ )) in left ventricular $d P / d t$ max, left ventricular end diastolic pressure (LVEDP), pulmonary capillary wedge pressure (PCWP), and stroke volume index (SVI) 30 minutes after amiodarone infusion as a percentage of baseline values. The patients are divided into two subgroups-those with minimal $(\leqslant 5 \%)$ changes of systemic vascular resistance (that is afterload unchanged) and those with a reduction in systemic vascular resistance or in left ventricular aortic pressure gradient (that is afterload decreased). patients with hypertrophic cardiomyopathy and that the main changes are a slight depression of cardiac function that is well tolerated and adequately compensated for by systemic vasodilatation. Transient reduction in compliance caused by impaired relaxation cannot be excluded. The patients did not report any subjective side effects.

\section{References}

1 McKenna WJ, Harris L, Perez G, Krikler DM, Oakley CM, Goodwin JF. Arrhythmia in hypertrophic cardiomyopathy. II: Comparison of amiodarone and verapamil in treatment. Br Heart $J$ 1981;46:173-8.

2 McKenna WJ, Harris L, Rowland E, et al. Amiodarone for long-term management of patients with hypertrophic cardiomyopathy. Am J Cardiol 1984;54:802-10.

3 McKenna WJ, Oakley CM, Krikler DM, Goodwin JF. Improved survival with amiodarone in patients with hypertrophic cardiomyopathy and ventricular tachycardia. Br Heart $J$ 1985;53:412-6.

4 Côté P, Bourassa MG, Delaye J, Janin A, Froment R, David P. Effects of amiodarone on cardiac and coronary hemodynamics and on myocardial metabolism in patients with coronary artery disease. Circulation 1979;59:1165-72.

5 Schwartz A, Shen E, Morady F, Gillespie K, Scheinman $M$, Chatterjee $K$. Hemodynamic effects of intravenous amiodarone in patients with depressed left ventricular function and recurrent ventricular tachycardia. Am Heart J 1983;106:848-56.

6 Bopp P, Rasoamanambelo L, Crevoisier JL, et al. Acute hemodynamic effects of intravenous amiodarone in patients with coronary artery disease. $J$ Cardiovasc Pharmacol 1985;7:286-89.

7 Maron BJ, Gottdiener JS, Epstein SE. Patterns and significance of distribution of left ventricular hypertrophy in hypertrophic cardiomyopathy. Am J Cardiol 1981;48:418-28.

8 Weiss JL, Frederiksen JW, Weisfeldt ML. Hemodynamic determinants of the time-course of fall in canine left ventricular pressure. J Clin Invest 1976; 58:751-60.

9 Holt DW, Tucker GT, Jackson PR, Storey GCA. Amiodarone pharmacokinetics. Am Heart J 1983; 106:840-6.

10 Haffajee CI, Love JC, Alpert JS, Asdowian GK, Sloan KC. Efficacy and safety of long-term amiodarone in treatment of cardiac arrhythmias: dosage experience. Am Heart $J$ 1983;106:935-43.

11 Kaski JC, Girotti LA, Messuti H, Rutitzky B, Rosenbaum MB. Long-term management of sustained, recurrent, symptomatic ventricular tachycardia with amiodarone. Circulation 1981;64:273-79.

12 Benaim R, Uzan C. Les effets antiarrhythmiques de l'amiodarone injectable (à propos de 153 cas). Rev Méd 1978;19:1959-63.

13 Morady F, Scheinman MM, Shen E, Shapiro W, Sung $\mathrm{RJ}$, Di Carlo L. Intravenous amiodarone in the acute treatment of recurrent symptomatic ventricular tachycardia. Am J Cardiol 1983;51:156-9.

14 Installe E, Schoevaerdts JC, Gadisseux Ph, Charles S, 
Tremouroux J. Intravenous amiodarone in the treatment of various arrhythmias following cardiac operations. J Thorac Cardiovasc Surg 1981;81:302-8.

15 Sugrue DD, Dickie S, Myers MJ, Lavender JP, McKenna WJ. Effect of amiodarone on left ventricular ejection and filling in hypertrophic cardiomyopathy as assessed by radionuclide angiography. Am J Cardiol 1984;54:1054-8.

16 Paulus WJ, Nellens P, Heyndrickx GR, Andries E. Effects of long-term treatment with amiodarone on exercise hemodynamics and left ventricular relaxation in patients with hypertrophic cardiomyopathy. Circulation 1986;74:544-54.

17 Sicart M, Besse P, Choussat A, Bricaud H. Action hémodynamique de l'amiodarone intra-veineuse chez l'homme. Arch Mal Coeur 1977;70:219-27.

18 Ourbak P, Rocher R, Aziza JP, et al Effets hémodynamiques de l'injection intra-veineuse de chlorhydrate d'amiodarone chez le sujet normal et le coronarien. Arch Mal Coeur 1976;69:293-8.

19 Remme WJ, Van Hoogenhuyze DCA, Krauss XH,
Hofman A, Kruyssen DACM, Storm CJ. Acute hemodynamic and antiischemic effects of intravenous amiodarone. Am J Cardiol 1985;55:639-44.

20 Bellotti G, Silva LA, Filho AE, et al. Hemodynamic effects of intravenous administration of amiodarone in congestive heart failure from chronic Chagas' disease. Am J Cardiol 1983;52:1046-9.

21 Kosinski EJ, Albin JB, Young E, Lewis SM, LeLand S Jr. Hemodynamic effects of intravenous amiodarone. J Am Coll Cardiol 1984;4:565-70.

22 Charlier $R$. Cardiac actions in the dog of a new antagonist of adrenergic excitation which does not produce competitive blockade of adrenoreceptors. $\mathrm{Br}$ $J$ Pharmacol 1970;39:668-73.

23 Bauthier J, Broekhuysen J, Charlier R, Richard J. Nature of the inhibition by amiodarone of isoproterenol induced tachycardia in the dog. Arch Int Pharmacodyn Ther 1976;219:45-51.

24 Nokin $P$, Clinet $M$, Schoenfeld P. Cardiac $\beta$-adren- $\overrightarrow{+}$ oceptor modulation by amiodarone. Biochem Pharmacol 1983;32:2473-7. 